\title{
ERP Systems in SMEs: An Extended Literature Review
}

\author{
Moutaz Haddara ${ }^{1, *}$, Ondrej Zach ${ }^{2}$ \\ ${ }^{1}$ Department of Information Systems, University of Agder, Kristiansand, 4604, Norway \\ ${ }^{2}$ SAP Consultant, Hewlett Packard, Prague, 140 21, Czech Republic
}

\begin{abstract}
This review summarizes research on enterprise resource planning (ERP) systems within the domain of small and medium-size enterprises (SMEs). Due to the close-to-saturation of ERP adoptions in large enterprises (LEs), ERP vendors now focus more on SMEs. Moreover, because of globalization, partnerships, value networks, and the huge information flow across and within SMEs nowadays, mo re and mo re SMEs are adopting ERP systems. Risks of adoption rely on the fact that SMEs have limited resources and specific characteristics that make their case different from LEs. The main purpose of this article is to shed the light on the areas that lack sufficient research within the ERP in SMEs do main, suggest future research avenues, as well as, present the current research findings that could aid practitioners, suppliers, and SMEs when embarking on ERP projects. Moreover, this research highlights the theories, frame works, and research approaches and methods currently adopted in ERP for SMEs literature.
\end{abstract}

Keywords ERP, SMEs, Literature Review

\section{Introduction}

ERP systems have received a substantial attention from both academia and practice. Many research articles dealing with ERP systems have been published, covering various topics and issues. Moreover, a number of ERP literature reviews have been conducted[e.g., 1, 2-4]. These reviews provide overviews of existing ERP literature from a general point of view. Since ERP literature is a broad topic, we focused our review on ERP in SMEs that would provide a more detailed analysis and deeper understanding of this domain.

SMEs have been recognized as fundamentally different environments compared to large enterprises [5]. In relation to ERP implementations, organizational size plays an important role[6, 7]. The literature argues that little attention has been given to research on ERP in SMEs, as the majority of the ERP studies are based on findings from

large enterprises $[8,9]$. Up to our knowledge, there are no existing literature reviews covering this particular area.

The objective of this paper is to present a comprehensive review of literature on ERP in SMEs in order to illustrate the status of research in this area, and to assist researchers in pinning down the current res earch gaps. A total of 77 articles were reviewed and organized into ERP life-cycle phases as described by Esteves et al.[10].

The rest of the paper is organized as follows. Section 2 presents the research methodology. Section 3 provides an

* Corresponding author:

Moutaz.Haddara@uia.no (Moutaz Haddara)

Published online at http://journal.sapub.org/ijis

Copyright (C) 2012 Scientific \& Academic Publishing. All Rights Reserved overview of the articles reviewed. Section 4 provides our findings. Section 5 discusses our observations and recommendations for future research. Finally section 6 , discusses the paper implications on research and practice.

\section{Research Methodology}

Literature reviews represent a well-established method for accumulating existing knowledge within a domain of interest. In this article we have applied a systematic review approach [11]. This approach is characterized by adopting explicit procedures and conditions that minimize bias[11].

The review covers articles published between the years 1999-2009. We have narrowed down the search process through a condition, that the artic les need to be published in peer reviewed journals or conference proceedings. Moreover, no delimitation has been imposed on the outlets' field, to enable potential research results from various fields. The following search procedures have been applied to provide a comprehensive and systematic methodology.

An initial search was done through Google Scholar. The search option was limited to articles' titles. The keywords: ERP, Enterprise Recourse Planning, SMEs, Small and Medium Enterprises, and their co mbinations were used.

1. Due to their high relevance for IS research, another search in EBSCOhost and Web of Science was conducted. The search procedure was restricted to the same keywords as in the previous step. In addition to the title area, the abstract and keyword parts of the articles have been included into the search.

2. In order to ensure that no articles were omitted by the search engines used in the previous steps, we went through 
tables of contents of selected outlets. These included top IS journals (MISQ, ISR, CACM, JMIS, ISJ, and EJIS) and journals related to the research field (JEIM, EIS, and IJEIS). We searched for the keywords across all issues published during the delimitated period. The same procedure was applied to the proceedings of four top IS conferences (ICIS, ECIS, AMCIS, HICSS).

3. Both authors carefully read the articles' abstracts to check their relevance and adequacy for the review. Only articles directly addressing ERP in SMEs were selected.

4. In addition, we conducted a secondary search through scanning all the selected articles' reference lists, in order to identify further potential literature sources.

In order to better organize the review arrangement, we adopted the ERP life-cycle framework developed by Esteves et al.[10]. It consists of six phases representing different stages an ERP system goes during its life-cycle within an organization. The phases are: adoption decision, acquisition, implementation, use and maintenance, evolution, and retirement. A brief description of each phase is provided in section 4 . In addition, the authors independently classified the articles into a concept matrix[12], which included the research themes, approaches, theories, and methodologies. Results were consequently compared and discussed in order to achieve consensus on the articles' classification. It is important to mention that an article could fall in one or more phases and themes.

A number of research artic les proposed various ERP life cycle models [e.g., 10, 13, 14, 15]. There are two important reasons why we adopted Esteves et al.[10] framework. First, it applies more granular approach compared to other models. It provides more detailed understanding of the ERP life-cycle and thus better classification of the articles. In particular, the framework clearly distinguishes between system adoption and acquisition, as these are two diverse phases that are usually merged in other models. Furthermore, the framework separates between system evolution and retirement. Second, it has been previously applied by other researchers reviewing ERP literature[3, 16]. This enables a comparability of our findings with formal literature reviews.

\section{Overview of the Articles}

In total, we reviewed 77 articles. Of these, 48 are journal articles and 29 conference proceedings. The articles were published in 44 various outlets, involving 26 journals and 18 conferences. As illustrated in tables 1 and 2 , journals had the biggest share of publications with JEIM leading by 10 articles, and AMCIS by 5 conference publications.

The review shows a gradual increase in research interest in ERP in SMEs (fig 1.), with a maximum of 20 publications in 2008 followed by a decline to 11 articles in 2009 . Figure 2 illustrates the research methods distribution among the articles. Case studies and surveys are clearly the dominant methods, while other methods are comparably less frequently used.
Table 1. Journal outlets and publications

\begin{tabular}{|c|c|}
\hline Journal & $\begin{array}{l}\text { Number of } \\
\text { publications }\end{array}$ \\
\hline Benchmarking: An International Journal (BIJ) & 1 \\
\hline Business Information Systems (BIS) & 1 \\
\hline Business Process Management Journal (BPMJ) & 3 \\
\hline $\begin{array}{l}\text { Communication of the Associat ion for Comput ing } \\
\text { Machinery (CACM) }\end{array}$ & 1 \\
\hline $\begin{array}{c}\text { Communications of the Association for } \\
\text { Information Systems (CAIS) }\end{array}$ & 1 \\
\hline $\begin{array}{c}\text { Communication of the International Information } \\
\text { Management Association (IIMA) }\end{array}$ & 1 \\
\hline European Management Journal (EMJ) & 1 \\
\hline Engineering Letters Journal (IAEG) & 1 \\
\hline Industrial Management and Data Systems (IMDS) & 3 \\
\hline Information Systems Journal (ISJ) & 2 \\
\hline Information Systems Management (ISM) & 1 \\
\hline $\begin{array}{c}\text { Int ernat ional Journal of Enterprise Informat ion } \\
\text { Systems (IJEIS) }\end{array}$ & 2 \\
\hline $\begin{array}{c}\text { Int ernat ional Journal of Enterprise Net work } \\
\text { Management (IJENM) }\end{array}$ & 1 \\
\hline $\begin{array}{c}\text { International Journal of Integrated Supply } \\
\text { Management (IJISM) }\end{array}$ & 1 \\
\hline $\begin{array}{c}\text { Int emat ional Journal of Operat ions and } \\
\text { Production Management (IJOPM) }\end{array}$ & 2 \\
\hline $\begin{array}{l}\text { Int emational Journal of Production Economics } \\
\text { (IJPE) }\end{array}$ & 4 \\
\hline $\begin{array}{l}\text { Int emational Journal of Product ion Research } \\
\text { (IJPR) }\end{array}$ & 3 \\
\hline $\begin{array}{l}\text { Int emat ional Journal of Project Management } \\
\text { (IJPM) }\end{array}$ & 1 \\
\hline Journal of Accountancy (JofA) & 1 \\
\hline $\begin{array}{l}\text { Journal of Ent erprise Information Management } \\
\text { (JEIM) }\end{array}$ & 10 \\
\hline $\begin{array}{c}\text { Journal of Manufacturing Technology } \\
\text { Management (JMTM) }\end{array}$ & 2 \\
\hline $\begin{array}{l}\text { The Journal of Strat egic Information Systems } \\
\text { (JSIS) }\end{array}$ & 1 \\
\hline Journal of Information T echnology (JIT) & 1 \\
\hline $\begin{array}{c}\text { Int ernational Journal of Procurement } \\
\text { Management (IJPM) }\end{array}$ & 1 \\
\hline Media Informatika & 1 \\
\hline $\begin{array}{l}\text { Omega (The Int ernational Journal of Management } \\
\text { Science) }\end{array}$ & 1 \\
\hline \begin{tabular}{|c|c} 
Total & 26 \\
\end{tabular} & 48 \\
\hline
\end{tabular}

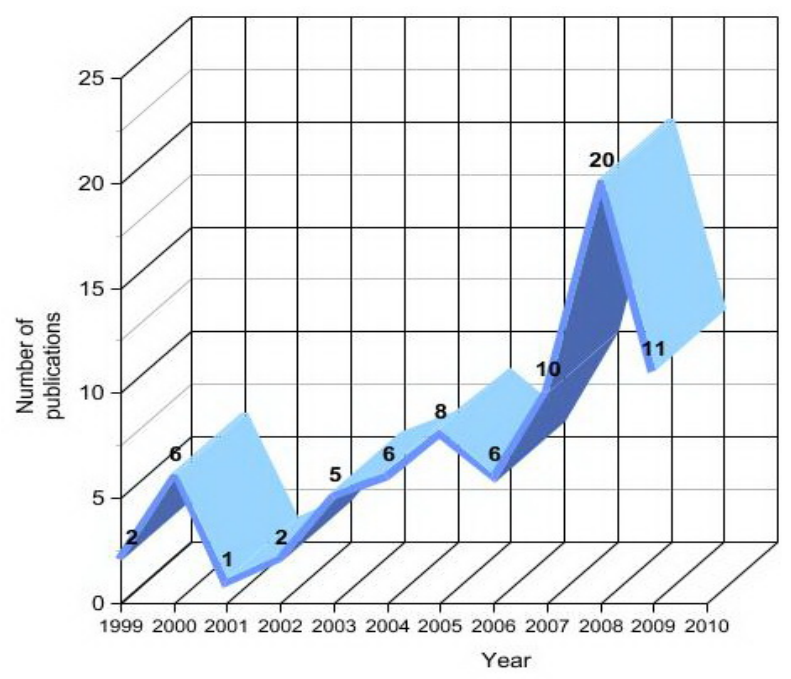

Figure 1. Number of publications per year 
Table 2. Conference out lets and publications

\begin{tabular}{|c|c|}
\hline Conference & $\begin{array}{l}\text { Number of } \\
\text { publications }\end{array}$ \\
\hline AIM International Conference & 1 \\
\hline $\begin{array}{c}\text { Americas Conference on Information Systems } \\
\text { (AMCIS) }\end{array}$ & 5 \\
\hline Annual SAP Asia Pacific & 1 \\
\hline $\begin{array}{l}\text { Australasian Conference on Information Systems } \\
\text { (ACIS) }\end{array}$ & 2 \\
\hline $\begin{array}{c}\text { European and Mediterranean Conference on } \\
\text { Information Systems (EMCIS) }\end{array}$ & 2 \\
\hline $\begin{array}{l}\text { European Conference on Information Systems } \\
\text { (ECIS) }\end{array}$ & 2 \\
\hline Frontier of e-Business Research (FeBR) & 1 \\
\hline GMSARN International Conference & 1 \\
\hline $\begin{array}{c}\text { Hawaii International Conference on System } \\
\text { Sciences (HICSS) }\end{array}$ & 3 \\
\hline $\begin{array}{c}\text { International Conference on Enterprise } \\
\text { Information Systems (ICEIS) }\end{array}$ & 2 \\
\hline $\begin{array}{l}\text { Internat ional Conference on Informat ion Systems } \\
\text { (ICIS) }\end{array}$ & 1 \\
\hline $\begin{array}{c}\text { International Engineering Management } \\
\text { Conference }\end{array}$ & 1 \\
\hline $\begin{array}{c}\text { Internat ional MCETECH Conference on } \\
\text { eT echnologies }\end{array}$ & 1 \\
\hline $\begin{array}{l}\text { Internat ional Conference on Management of } \\
\text { Innovation and Technology (ICMIT) }\end{array}$ & 1 \\
\hline $\begin{array}{c}\text { International Conference on Service Systems and } \\
\text { Service Management }\end{array}$ & 1 \\
\hline $\begin{array}{l}\text { Pacific Asia Conference on Information Systems } \\
\text { (PACIS) }\end{array}$ & 2 \\
\hline $\begin{array}{l}\text { Stimulating Manufact uring Excellence in Small } \\
\text { and Medium Enterprises Conference (SMESME) }\end{array}$ & 1 \\
\hline $\begin{array}{l}\text { World Multi-conference on Systemics, } \\
\text { Cybernetics and Informatics (SCI) }\end{array}$ & 1 \\
\hline \begin{tabular}{l|c} 
Total & 18 \\
\end{tabular} & 29 \\
\hline
\end{tabular}

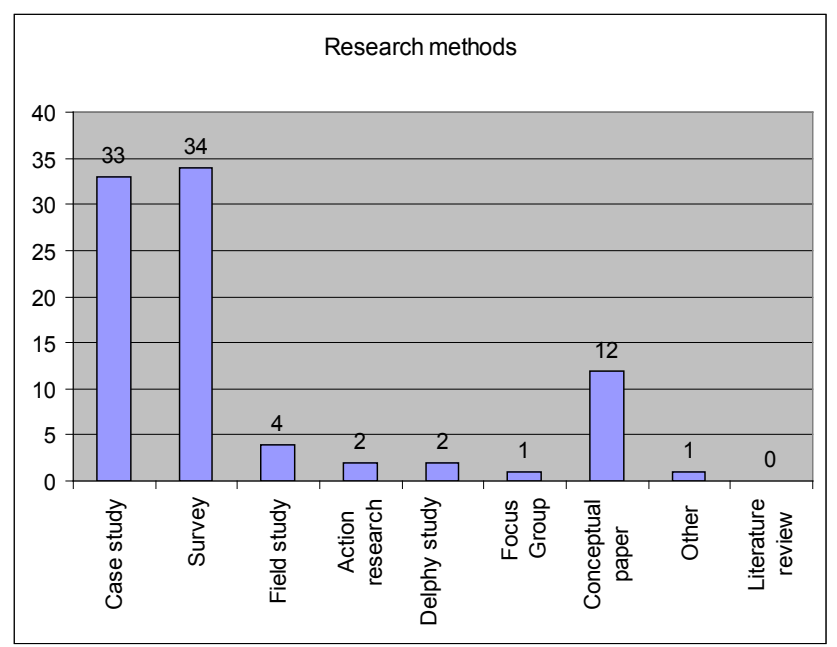

Figure 2. Research methods

As shown in Figure 3, the implementation is the most discussed phase in literature, which is in alignment with several formal literature reviews on ERP systems[3, 16]. Moreover, the figure illustrates the clear difference of research focus among the phases.

Table 4 provides a list of publications that have adopted theories or established frameworks. Some papers have adopted more than one theoretical lens. The richness of theory or framework use varies among articles; however, we list the articles that explicitly mentioned their adoption and use of theories.

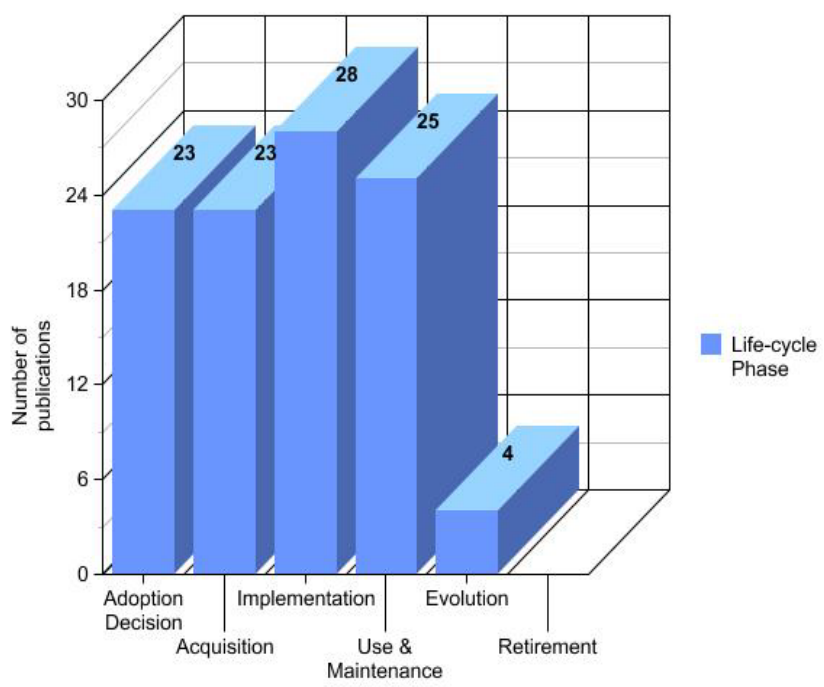

Figure 3. ERP life cycle

\section{Findings}

In this section, a brief overview of the articles for each phase is presented. It is not intended to provide a detailed discussion of each article, but rather an attempt to briefly present the topics and issues discussed in literature. For the articles reviewed in each phase, refer to Table 3 below.

Table 3. Article cat egorization

\begin{tabular}{|c|c|c|}
\hline $\begin{array}{l}\text { Life-cycle } \\
\text { phase }\end{array}$ & Issues & Reference articles \\
\hline \multirow{4}{*}{$\begin{array}{l}\text { Adoption } \\
\text { decision }\end{array}$} & Adoption drivers & {$[6,7,17-26]$} \\
\hline & Adoption evaluation & {$[17,22,24-31]$} \\
\hline & $\begin{array}{l}\text { Organizational } \\
\text { characteristics }\end{array}$ & {$[6,7,22,24,26,31,32]$} \\
\hline & Other adoption issues & {$[8,14,28,33-35]$} \\
\hline \multirow{4}{*}{ Acquisition } & $\begin{array}{c}\text { Factors affecting } \\
\text { selection }\end{array}$ & {$[18,19,36-41]$} \\
\hline & Selection criteria & {$[29,38,39,42-44]$} \\
\hline & $\begin{array}{c}\text { In-house developed } \\
\text { systems }\end{array}$ & {$[45-47]$} \\
\hline & Other acquisition issues & {$[8,14,33,42,47-52]$} \\
\hline \multirow{5}{*}{$\begin{array}{l}\text { Implement- } \\
\text { ation }\end{array}$} & CSFs & {$[9,40,41,49,53-57]$} \\
\hline & SME characteristics & {$[6,50,53,57-60]$} \\
\hline & Impact of consultant & {$[58,61,62]$} \\
\hline & Risk management & {$[33,48,63]$} \\
\hline & $\begin{array}{c}\text { Other implementation } \\
\text { issues }\end{array}$ & $\begin{array}{c}6,8,14,40,62,64-69, \\
81]\end{array}$ \\
\hline \multirow{3}{*}{$\begin{array}{l}\text { Use and } \\
\text { maintenance }\end{array}$} & Benefits & {$[6,40,41,70-77]$} \\
\hline & Use & $\begin{array}{c}{[6,14,48,50,63,77-81,} \\
85]\end{array}$ \\
\hline & ERP impact & {$[36,37,82-84]$} \\
\hline Evolution & & {$[14,86-88]$} \\
\hline Retirement & - & - \\
\hline
\end{tabular}


Table 4. Adopted theories \& frameworks

\begin{tabular}{|c|c|}
\hline Theory/framework & Reference articles \\
\hline Dialectic perspect ive & {$[60,81]$} \\
\hline Process theory & {$[9,14]$} \\
\hline $\begin{array}{c}\text { Technology-Organization Environment } \\
\text { framework }\end{array}$ & {$[20,21]$} \\
\hline IT Conversion theory & {$[88]$} \\
\hline Punctuated Equilibrium theory & {$[66]$} \\
\hline Social Process theory & {$[66]$} \\
\hline Grounded Theory & {$[14,61,62]$} \\
\hline Innovation Diffusion theory & {$[33,51]$} \\
\hline Organizational Changetheory & {$[33]$} \\
\hline Neo-institutional theory & {$[33]$} \\
\hline Complexity theory & {$[33]$} \\
\hline
\end{tabular}

\subsection{Adoption Decision}

During this phase, organizations identify their business and technical needs, and question the need for an ERP system. Current ERP literature has tackled several issues related to ERP adoptions in an SME context and environment.

Adoption drivers. Several papers discussed ERP adoption drivers in SMEs from different angles. Few studies [20, 21] have adopted the Technology-Organization Environment framework (TOE) to develop a model that can be applied to predict which SMEs are mo re likely to become adopters of Enterprise Systems (ES). Although, the model developed was applied to predict the factors influencing the willingness of SMEs to adopt ES, nevertheless it does not differentiate between factors that affect each type of system solely (e.g. ERP, SCM). In $[20,21]$ they concluded that SMEs' ES adoptions are more influenced by internal organizational and technological factors, sooner than industry and market related factors. On the contrary, a study[23] suggests that, the higher an SME collaboration within a network of organizations, the more likely to adopt an ES, and more environmental influence it will get.

Adoption evaluation. A study conducted in Ind ia argues that business needs, competition, market survival, and customer retention are among the main drivers that force SMEs to adopt ERP system[29]. Ravarini et al.[30] propose a pre-adoption framework for evaluating the suitability of an ERP system in alignment with the degree of business complexity, and the extent of change that a company envisions to achieve. Blackwell et al.[27] developed a decision-support systematic methodology that assists decision makers in regard to adoption decisions and could enhance the overall outcomes from the ERP adoption project. Other studies states that CEO's characteristics and the ERP perceived benefits are correlated with ERP adoptions' outcomes in Taiwanese SMEs[25]. ERP cost per se is not a major factor in adoption decisions[25], especially in the adoption or non-adoption of free open source ERP systems in comparis on to proprietary ERPs[17].

Organizational characteristics. Other researchersstudied the influence of specific organizations' characteristics on
ERP adoption decisions. Research results shows that business complexity is a weak predictor of ERP adoption[7], while organizat ion size is a strong adoption predictor[6, 7, 22, 26]. Moreover, SMEs' willingness and readiness of adopting ERP systems are affected by industry type in manufacturing firms [22, 31]. Other studies argue that the scarcity of financial resources, and the challenges that face SMEs while evaluating and selecting ERP do not have an influence on ERP adoption decisions[24], and that adoption drivers may vary according to SME size[32].

Other adoption issues. Several adoption-related issues were discussed in literature. A study by Muscatello et al.[8] reported that project management activities have a huge influence on the success or failure of ERP adoption projects in US manufacturing SMEs. On the contrary, another research shows that formalized management does not promise implementation risk minimization in small manufacturing companies[33]. In[34, 35] they developed and applied a multi-disciplinary Customer-Centered ERP Implementation (C-CEI) method. They present C-CEI as a tool that could assist SMEs in selecting appropriate ERP Systems, which match their process requirements. They argue that this method would decrease the risk of ERP and organizations misalign ment.

One of the few ERP marketing studies has been done by [28]. The research had a vendor-customer perspective. The paper construes that ERP suppliers' marketing abilities and customer reach strategies determine ERP diffusion and adoption success in SMEs, rather than SMEs' low demand or failure in the adoption process.

\subsection{Acquisition}

This phase includes the process of ERP package and vendor selection that best fit the organization require ments.

Factors affecting selection. In order to better understand and evaluate the acquisition and selection process, many studies identified the factors that affect ERP selection in SMEs, and proposed criteria to optimize the selection process. Results show that internal organizational factors like business complexity, change management, and external factors like supply chain partners, and the pressure of value networks affects the ERP selection process in Greek SMEs [36-38]. While other res earch conducted in Australian SMEs, suggest that cost drivers, functional requirements, flexibility, and scalability of the ERP system[41], and the degree of ERP alignment/fit with the business processes[40] have a great influence on acquisition decisions. Moreover, in $[18,19]$, they compared Finnish small, medium, and large enterprises. They explored the relationship of enterprise size with the ERP selection process. Their results show that small companies appear to have problems with the ample information for decision-making, and sufficiency of participation from different organizational functions in the ERP system selection phase.

Selection criteria. This part presents research that developed or explored the criteria that SMEs use in order to 
select their ERP systems. In[44], they stated that the ERP fit with organization business processes appeared to be the most important selection criterion in Nordic European SMEs, whilst others developed criteria that can aid SMEs in the selection process. The dimensions were local support, affordability, suppliers' business domain knowledge[29], or a methodology for selecting the best-fit ERP system with make-to-order (MTO) SMEs' environ ments [39].

In-house de veloped systems. In ERP for SMEs literature, few research papers questioned the feasibility of in-house developed systems over off-the-shelf ERPs as in[45, 46]. These papers argue that standard ERP packages could compel rigid structures and inflexibility on niche SMEs, and in-house developed systems might be more suitable in some cases. Correspondingly, Sledgianowski et al.[47] conducted a case study and reported that in some cases, ERP offshore outsourcing could be more feasible and beneficial for SMEs.

Other ac quisition issues. CEOs' technology awareness, emp loyees' IT competence, firm size, ERP co mpatib ility[49, 51], and project management[8], are among the CSF for selecting the right ERP for SMEs. Other researchers furnished recommendations and methods that could be of assistance in managing and minimizing the key risk factors during the ERP selection process [33, 48]. Other studies went further and conducted a comparative analysis of the impact of size on the selection procedures in LEs and SMEs [42, 52], as well as, across industrial sectors in Taiwan[50].

\subsection{Implementation}

This phase includes the actual ERP installation, customization, business process re-engineering (BPR), and all other activities that align the system with the organization requirements. The ERP implementation phase is very critical, as well as, the most resource consuming phase. Several studies focused on different corners during the implementation process.

Critical success factors. The adequacy of general-ERP implementations CSF in relation to Belgian SMEs-specific characteristics were examined in[53]. The study discovered that most of ERP CSF apply to SMEs with some exceptions. Likewise, a study analyzed implementation success factors in small size firms and concluded that the CSF in literature are adequate when applied on small organizations[49]. Another article presented an analysis of the CSF related to Chinese SMEs' characteristics[57]. While top management support, ERP system quality, and knowledge sharing during implementations, were found key CSF in Thai SMEs [54], however, BPR was found to be a key factor of success [57].

In[56], the authors developed a framework for ERP implementation CSF assessment in small manufacturing firms. Moreover, Loh et al.[9] used the Process Theory in order to identify the implementation critical elements through case studies in the UK. The study concluded that critical success factors, critical people and critical uncertainties contribute to the success or failure of ERP implementations in SMEs. Reuther et al.[41] and Marsh[40] carried out an analysis to determine the key success and failure factors of ERP implementations in Australian SMEs. Further, in Snider et al.[55], they presented a detailed case analysis of successful and unsuccess ful implementations in five Canadian SMEs. Finally, a new CSF ranking that would be more adequate to SMEs environments is needed[57].

SME characteristics. As organization-specific characteristics and contexts have been always important research aspects, they attracted researchers to investigate their implications on the ERP implementation process. A study presented a conceptual model that could help implementers, vendors, and consultants implementing SAP $\mathrm{R} / 3$ ERP to better understand the system expectations by SMEs in certain contexts or regions (e.g. Australia)[59]. Since organization size and business complexity affect ERP implementations, it was reported that implementations in Irish SMEs are usually easier and shorter in duration than those reported in ERP literature[58]. In[60], through adopting a vendor's perspective, they recommend that ERP systems need to be localized according to the local management features. SMEs' characteristics and culture play an important role in the success or failure of ERP implementations in Belgian SMEs[53], while cultural issues did not play a major role in ERP implementations within Chinese SMEs [57]. Moreover, ERP implementation methodologies differ between different organization sizes and business complexities, as LEs are more reluctant to adopt a Big-Bang approach than SMEs[6]. Further, a comparative analysis on ERP implementation rates and success, between different organization sizes and industrial sectors in Taiwan shows that ERP implementations in electronic and science industry SMEs are usually more successful than those in traditional industry[50]

Impact of consultants. Although experienced consultants can play an important role in correcting their client companies' "unrealistic expectations" of ERP implementation s [58]; however, a study in Taiwan shows that consultants could still face resistance from SMEs' managers [58]. On the contrary, through Grounded Theory approach,[62] states that if SMEs implement an SME-specific ERP system, they will not need external consultancy, which will decrease their investments dramatically. Moreover, SMEs will save time and high costs of training, which are usually, as sociated with standard ERP packages.

Risk management. Few papers discussed risk management during ERP implementations in SMEs. In[63], they portrayed how SMEs should deem and manage the risks in their ERP implementation projects. Poba-Nzaou et al. [33] discuss methods for ERP implementation risk management and minimization in manufacturing SMEs. Iskanius[48] applied and advocated for using the risk analysis method (RAM), to identify and asses the critical risks of the ERP implementations, and to apply the characteristics analys is method (CAM) in order to help SMEs in dividing ERP implementation projects into sub-projects.

Other implementation issues. Project activities, coordination, and project sponsors [8], employee behaviour, 
individual characteristics of ERP project management's team, and organization culture have a great effect on the success of ERP implementations in SMEs [64].

Chan[67] emphasized the importance of knowledge capturing and management during implementations in SMEs. The study identified the essential knowledge required for ERP implementations, and proposed a frame work to manage it, through matching the required knowledge with the ERP capabilities and features. Moreover, Zain[69] proposed the application of the FAST (Framework for Application of Systems Thinking) system development methodology while implementing ERP systems in cigarette manufacturing SMEs. The study concludes that using such an agile method could assist in reducing and filtering common problems that occur during ERP implementations.

Newman et al.[66] conducted a study on two Chinese small and medium companies. Through business process modeling, the study compares and analyzes the process of ERP implementation in these two companies, and discusses their decisions concerning business process re-engineering. Likewise, in[68], they emphasized the importance of business process modeling, management and re-engineering ex ante implementations. Their study was a simulation on niche Italian SMEs. They conclude that in some cases, ERP systems should be customized to fit with $n$ iche SMEs and not vice versa, as they might lose their competitive advantage by comply ing with standard ERP processes.

In comparison with LEs, SMEs suffer scarcity of financial resources; however, only two papers have discussed ERP costs in an SME context. Through a survey analysis, Equey et al.[65] investigated and evaluated the costs that occurred during ERP implementations in several Swiss SMEs. They found that size, consultants' experience, and people characteristics have a great influence on ERP projects costs. Moreover, implementations at larger companies generally cost much more than at smaller companies, however, a survey by Mabert et al.[6] shows that cost of ERP software at SMEs is higher as a percentage of overall cost than at LEs.

\subsection{Use and Maintenance}

After the sizeable efforts and investments in ERP implementations, companies start to use the systems. Many issues emerge after the systems" "go-live", like system acceptance, user satisfaction, benefits realization, system utilization, and maintenance.

Benefits. ERP benefits expectations and realization have always been problematic issues for the majority of companies. The difficulty originates to several reasons. Here we present some of the issues discussed in literature.

Although benefits realized could differ in each SME industry[41], or organization size[6], several studies argue that realizing benefits from ERP systems can not be done unless there has been an ex-ante efforts to define and audit these expected benefits[41, 70-72, 75]. However, if SMEs make the right choices in the ERP selection phase, some benefits from ERP systems could be self-evident[41, 73, 74] and tangible[40]. Moreover, a study in Swiss SMEs concludes that the benefits realized from ERP systems exceed their costs[76]. Whilst another study reports that benefits realized from ERP systems are higher in LEs than SMEs [77].

Use. Even if the ERP implementation was successful, for many practitioners and researchers, the usage of the systems is considered the moment of truth of an ERP system. If the implementation was successful but the system was not used or "accepted" by users, then it is considered a failure. Thus, many studies were focused on use, user motivation and satisfaction related is sues.

Adopting ERP's standard best practices is the aim of many SMEs, as they see it as a gateway for standardization and regional or international markets. However, through a dialectic perspective, Nathanael et al.[81] argue that best practices, when imposed on SMEs, might affect the motivation of the users, and lead to the loss of the know-how and the competitive edge of these companies. Moreover, if ERP systems were more agile and responsive, this would utilize the system use and offer a competitive edge for MTO and traditional manufacturing SMEs[78-80]. A case study results show that user satisfaction and system acceptance rates in LEs are higher than those of SMEs [77]. Further, Wu et al.[50] argue that user satisfaction in Taiwanese electronic and science industries' SMEs is higher than of LEs in the same industry and SMEs in other industrial sectors. In order to minimize the risk of challenges related to user acceptance and motivation, Huin[85] developed a multi-agent model that can decrease the risks related to system use and user acceptance, through organizing the ERP project management activities. In addition, enhancing user communication, training, and obtaining short-term successes could positively impact the motivation and users' system acceptance rates within SMEs [48]. In[63], they state that risk management is a continuous process. They also recommend that benefits and risks in the use and maintenance phase should be re-assessed once or twice a year, in order to manage the impact of stirring risks, and to govern system usage and avoid slipping into old procedures

ERP impact. Introductions of new information systems in companies are accompanied by changes with their business processes, structure, and communications within those companies. Likewise, ERP systems affect many corners within organizations. A case study in an MTO medium-sized company reports that, the ERP adoption had a positive impact on visibility, quality, and control of information, which in turn enhanced the decision making process [84]. Using the Six Imperatives framework, Argyropoulou et al. $[36,37]$ evaluated the impact of ERP systems on Greek SMEs' business performance. In[82], they attest that ERPs impact on productivity is moderated by SMEs size. Another study [83] adopted an organizational cross-functional point of view in order to evaluate the impact of ERP implementation on different business functions. The study concludes the smaller the size of the organization, the more it 
will benefit from the ERP system's cross-functionality capabilities.

\subsection{Evol ution}

This phase involves the extension of ERP systems through integrating other systems or applications, such as customer relationship managements, supply chain management, and advanced planning and scheduling systems.

In[86], the authors state that SMEs which had successful ERP system implementations, are now investigating means of how to extend it in order to support their external operations. The study concludes that, with the use of Internet, ERPs can be extended to cover SMEs' entire supply chain, which in turn will enhance their external operations and relationships. Another study developed an ontology-based conceptual framework. The study argues that, representing the implementation processes using ontology domains, classes, and relations could enhance the coordination and project management during ERP implementations in SMEs [88]. Further, Metaxiotis[87] carried out a study to investigate the raison d'être for integrating knowledge management (KM) systems and ERP systems in SMEs. The study suggested an ERP extension and KM integration framework.

\subsection{Retirement}

Retirement phase corresponds to the stage when an ERP system is substituted by another information system. No articles were identified in this phase.

\section{Discussion and Future Research Avenues}

The reviewed articles are spread across 44 various outlets. Among the outlets, we have recognized only one special journal issue in JEIM focusing on adoption of ICT by SMEs, which included several ERP related research papers. As the research interest on ERP in SMEs is increasing, research outlets should pay more attention to this domain.

In general, 77 articles across 10 years period is relatively a low nu mber of publications. Despite the need for research on ERP in SMEs was recognized in previous literature, still the amount of research conducted on this issue is limited. Thus, more research needs to be carried out in order to gather sufficient knowledge about this phenomenon, as SMEs did not receive appropriate attention in comparis on with ERP in LEs.

Based on our ERP in SMEs literature review, in the following part we present some research gaps and suggestions organized according to life-cycle phases:

Adoption. In IS literature in general, and in ERP literature in specific, the term "adoption" is variably perceived by authors. Some authors perceive it as a final stage in which users accept the ERP system, and others define it as the preliminary stage when companies decide on investing in an ERP system.
Although some papers tackled the pressures or motivations imposed by suppliers and partners for ERP adoptions by SMEs, still there is a gap in studying national government policies, rules and laws and their consequences on ERP adoptions in SMEs.

Acquisition. The current literature lacks focus on new technologies (e.g. Software as a Service-SaaS) and their implications on ERP projects. Moreover, ex-ante cost estimation, financial feasibility, and investment evaluation studies of ERP projects have not been identified in our review of literature. Furthermore, literature lacks cases that compare between SMEs'-specific ERP and general ERP systems, as well as, industry-specific ERP packages vs. general ERP ones.

Implementation. So me articles examined ERP projects' success and CSF in SMEs, however, there was no clear definition for success. Moreover, the differences of ERP implementation methodologies and their impact on ERP projects had scant attention.

Use and maintenance. Interface language and ERP localization and their effect on user satisfaction are rarely discussed in literature. In addition, post implementation audit strategies and ex-post investment and financial evaluations were not discussed in literature.

Evolution and retirement. Regarding the ERP life-cycle phases, the first four phases were noticeably captured in literature. As recently SMEs started to adopt ERP systems to enhance their operations, value networks, and expansion goals. Thus, it is not surprising to find very few papers discussing ERP evolution, as ERP systems require time to mature enough and recompense in order to convince organizations to extend them further.

We were not able to find any article that directly addresses the retirement phase. Thus, we recommend more focus on the evolution and retirement phases, as they can shed the light on the motivations for extending or replacing ERP systems.

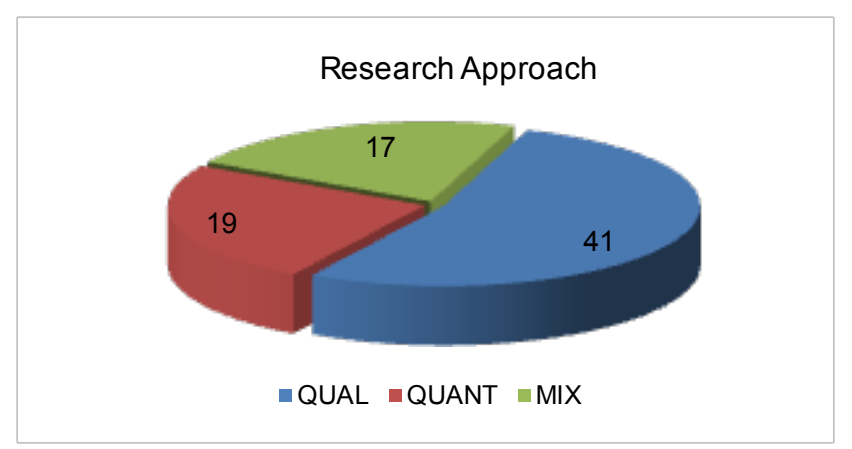

Figure 4. Adopted research approaches

General co mments. Although comparisons between SMEs and LEs cases were found in literature, yet the size differences among SMEs were seldom discussed, and they could provide valuable research insights. In relation to type of organizations, the cases studied were often conducted in traditional manufacturing SMEs. Only few articles elaborated on the manufacturing context or type of industry, 
however, difference in production strategies or industries could produce different research findings. Besides the SME type and context, another important observation evolved from our review, which is the "SMEs" perception. Some studies delimitate SMEs differently. So me research define an SME in a qualitative manner (e.g.[28]), while the majority of them define SME in terms of number of employees, annual revenue, or their co mb ination. However these numbers differ as well, particu larly depending on the geographical location of the study. Adopting the European Union's definition, most studies define SMEs as organizations with less than 250 emp loyees. Interestingly, some researchers have applied a more granular approach distinguishing between subgroups (e.g. s mall, micro) within SMEs (e.g.[16, 18, 19]). Both, type of investigated organizations and SME defin itions are likely to influence the research findings. Therefore, researchers need to be cautious about these issues and elaborate on specificity of each particular environ ment.

While there were many studies with a national perspective, however, we were not able to find any cross-national studies. This kind of comparison might be fruitful for ERP literature in SMEs. Also, most of the studies were embarked in America, Australia, Europe or Asia. It would be prolific to have some studies on African or Middle Eastern SMEs as well.

Surveys and questionnaires can be quantative or qualitative in nature. Although surveys were highly used, however, figure 4 . shows that $53 \%$ of the research publications have adopted a qualitative research approach. As many publications have reported that they conducted surveys, still they reported and analyzed them qualitatively, and only $25 \%$ of the publications have used a quantitative approach. According to Eisenhardt[89], multiple data collection methods could strengthens theory grounding and theory building through evidence triangulation. Thus, $22 \%$ of the studies have adopted mixed research approaches, through combining both qualitative and quantitative approaches and data collection methods. Most often a combination of case studies and surveys was employed. Qualitative studies can provide rich explanations and explorations to emerg ing phenomena; however, we call for a focus and use of other research approaches, as they can provide different angles of data interpretation. Moreover, use of theories in ERP literature in SMEs is very limited, as only $15 \%$ of the papers have adopted a theoretical lens (see fig. 5). This could be attributed to many reasons, among which, the complexity of finding relevant theories that could explain certain technical issues for example. Still, we call for more theory use, theorizing, and reporting on the difficulty of adopting theoretical lenses if any.

As shown in figure 2, only two Action Research (AR) papers were identified, however, we think that AR and similar engaged methods could provide very valuable hands-on experiences for ERP in SMEs literature and practice.

There is also a need for more papers on Open Source (OS) ERP systems, and comparative studies of OS ERP vs. proprietary ERP systems.

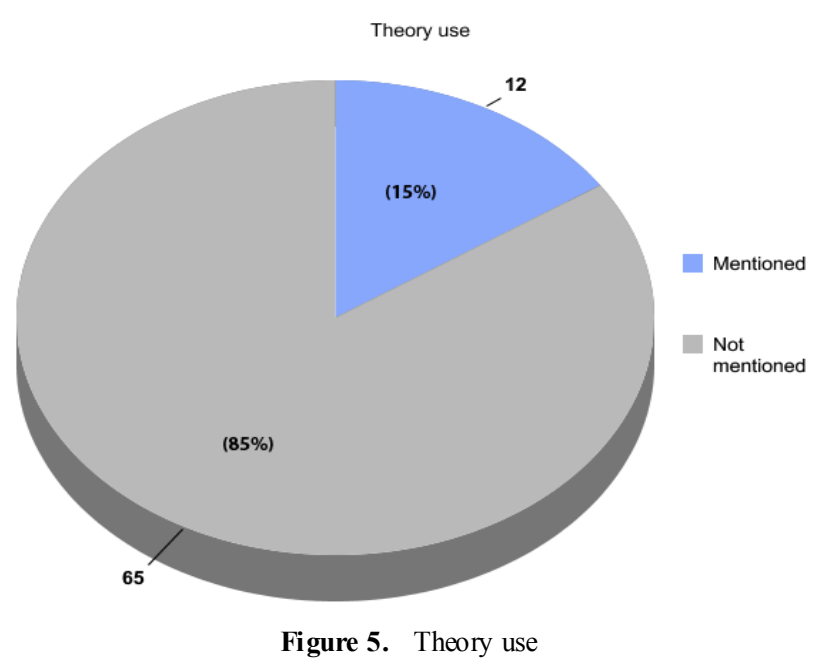

While SMEs usually have limited resources, and costs and benefits from ERP implementations continues to be an issue, more research need to address these topics.

Finally, existing literature have usually adopted a one sided perspective in data collection (e.g. customer side), while other perspectives could enhance the understanding of certain phenomena. Finally, it could be benefic ial if research provides some reports on ERP failure cases, which might assist stakeholders in avoiding previous pitfalls.

\section{Conclusions}

This paper contributes to both research and practice through providing a comprehensive literature review of ERP in SMEs. For practice, the paper sheds the light on past and recent issues, challenges, and success stories that can guide consultants, vendors, and clients in their future projects. For research, the organization of literature in ERP-lifecycle phases can aid them in identifying the topics, findings, research methods, theories, and gaps discussed in each phase of interest. Finally, we have provided our observations and future research suggestions that would enrich our knowledge in this domain.

\section{REFERENCES}

[1] E. M. Shehab, M. W. Sharp, L. Supramaniam, and T. A. Spedding, "Enterprise resource planning: An integrative review " Business Process Management Journal, 2004, vol. 10 , pp. 359.

[2] V. Botta-Genoulaz, P. A. Millet, and B. Grabot, "A survey on the recent research literature on ERP systems," Computers in Industry, vol. 56, 2005, pp. 510-522.

[3] J. Esteves and J. Pastor, "Enterprise resource planning systems research: An annotated bibliography," Communications of the Association for Information Systems, vol. 7, 2001. 
[4] Y. B. Moon, "Enterprise resource planning (ERP): a review of the literature " International Journal of Management and Enterprise Development vol. 4, 2007.

[5] J. A. Welsh and J. F. White, "A small business is not a little big business," Harvard Business Review, vol. 59, 1981, pp. $18-27$.

[6] V. A. Mabert, A. Soni, and M. A. Venkataramanan, "The impact of organization size on enterprise resource planning (ERP) implementations in the US manufacturing sector," Omega, vol. 31, 2003, pp. 235-246.

[7] G. Buonanno, P. Faverio, F. Pigni, A. Ravarini, D. Sciuto, and M. Tagliavini, "Factors affecting ERP system adoption: A comparative analysis between SMEs and large companies," Journal of Enterprise Information Management, vol. 18, 2005, pp. 384-426.

[8] J. R. Muscatello, M. H. Small, and I. J. Chen, "Implementing enterprise resource planning (ERP) systems in small and midsize manufacturing firms," International Journal of Operations and Production Management, vol. 23, 2003, pp. 850-871.

[9] T. C. Loh and S. C. L. Koh, "Critical elements for a successful enterprise resource planning implementation in small-and medium-sized enterprises," International Journal of Production Research, vol. 42, 2004, pp. 3433-3455.

[10] J. Esteves and J. Pastor, "An ERP Lifecycle-based Research Agenda," $1^{\mathrm{o}}$ International Workshop on Enterprise Management Resource and Planning Systems EMRPS, 1999, pp. 359-371.

[11] A. Bryman, Social Research Methods. New York: Oxford University Press, 2008.

[12] J. Webster and R. T. Watson, "Analyzing the past to prepare for the future: Writing a literature review," Mis Quarterly, vol. 26, 2002, pp. 13 .

[13] M. L. Markus and C. Tanis, "The Enterprise System Experience-From Adoption to Success," in Framing the Domains of IT Management: Projecting the Future Through the Past, R. W. Zmud, Ed. Cincinnatti, OH: Pinnaflex Educational Resources, Inc., 2000, pp. 173-207.

[14] S. I. Chang, D. C. Yen, S.-M. Huang, and P.-Q. Hung, "An ERP System Life Cycle-Wide Management and Support Framework for Small-and Medium-Sized Companies," Communications of the Association for Information Systems (CAIS), vol. 22, 2008, pp. 15.

[15] A. Parr and S. Graeme, "A model of ERP project implementation," Journal of Information Technology, vol. 15, 2000, pp. 289-303.

[16] J. Esteves and V. L. Bohórquez, "An Updated ERP Systems Annotated Bibliography: 2001 - 2005," Communications of the Association for Information Systems vol. 19, 2007, pp. 18 .

[17] B. Johansson and F. Sudzina, "ERP sy stems and open source: an initial review and some implications for SMEs," Journal of Enterprise Information Management, vol. 21, 2008, pp. 649.

[18] S. Laukkanen, S. Sarpola, and P. Hallikainen, "ERP System Adoption - Does the Size Matter?," in Hawaii International Conference on System Sciences (HICSS) 2005, pp. 226b-226b.
[19] S. Laukkan en, S. Sarpola, and P. Hallikain en, "Enterprise size matters: objectives and constraints of ERP adoption," Journal of Enterprise Information Management, vol. 20, 2007, pp. 319-334.

[20] B. Ramdani and P. Kawalek, "Predicting SMEs Willingness to Adapt ERP, CRM, SCM \& E-procurement Systems," in European Conference on Information Systems (ECIS), 2008.

[21] B. Ramdani, P. Kawalek, and O. Lorenzo, "Predicting SME's adoption of enterprise systems," Journal of Enterprise Information Managemen, vol. 22, 2009, pp. 10.

[22] L. Raymond and S. Uwizeyemungu, "A profile of ERP adoption in manufacturing SMEs," Journal of Enterprise Information Management, vol. 20, 2007, pp. 487-502.

[23] M. Schäfermeyer and C. Rosenkranz, "Inhibiting factors for adopting enterprise systems in networks of small and medium-sized enterprises - an exploratory case study," in Americas Conference on Information Systems (AMCIS), Toronto, ON, Canada, 2008.

[24] R. Seethamraju and J. Seethamraju, "Adoption of ERPs in a Medium-sized Enterprise - A Case Study," in Australasian Conference on Information Systems (ACIS), Christchurch, 2008.

[25] W. L. Shiau, P.-Y. Hsu, and J.-Z. Wang, "Development of measures to assess the ERP adoption of small and medium enterprises," Journal of Enterprise Information Management, vol. 22, 2009, pp. 99.

[26] M. Tagliavini, P. Faverio, A. Ravarini, F. Pigni, and G. Buonanno, "Exploring the use of ERP systems by SMEs," in World Multiconference on Systemics, Cybernetics and Infomatics (SCI), Orlando, FL, 2002.

[27] P. Blackwell, E. M. Shehab, and J. M. Kay, "An effective decision - support framework for implementing enterprise information systems within SMEs," International Journal of Production Research, 2006, vol. 44, pp. 3533-3552.

[28] V. Morabito, S. Pace, and P. Previtali, "ERP Marketing and Italian SMEs," European Management Journal, vol. 23, 2005, pp. 590-598.

[29] S. S. Rao, "Enterprise resource planning: business needs and technologies," Industrial Management and Data Systems, vol. 100, 2000, pp. 81-88.

[30] A. Ravarini, M. Tagliavini, F. Pigni, and D. Sciuto, "A framework for evaluating ERP acquisition within SMEs," in AIM International Conference, Montpellier, 2000, pp. 1-11.

[31] L. Raymond, S. Rivard, and D. Jutras, "Evaluating Readiness for ERP Adoption in Manufacturing SMEs," International Journal of Enterprise Information Systems, vol. 2, 2006, pp. $1-17$.

[32] P. Iskanius, R. Halonen, and M. Mottonen, "Experiences of ERP Use in Small Enterprises," in International Conference on Enterprise Information Systems (ICEIS), 2009.

[33] P. Poba-Nzaou, L. Raymond, and B. Fabi, "Adoption and risk of ERP systems in manufacturing SMEs: a positivist case study," Business Process Management Journal, vol. 14, 2008, pp. 530 .

[34] I. Vilpola and I. Kouri, "Improving ERP Requirement Specification Process of SMEs with a Customer-Centered 
Analy sis Method," in Frontier of e-Business Research (FeBR), Tampere, 2005, pp. 140-151.

[35] I. Vilpola, I. Kouri, and K. Vaananen-Vainio-Mattila, "Rescuing Small and Medium-Sized Enterprises from Inefficient Information Systems--A Multi-disciplinary Method for ERP System Requirements Engineering," in Hawaii International Conference on System Sciences (HICSS), 2007.

[36] M. Argyropoulou, G. Ioannou, D. Koufopoulos, and J. Motwani, "Performance drivers of ERP systems in small - and medium - sized enterprises," International Journal of Enterprise Network Management, vol. 2, 2008, pp. 333.

[37] M. Argyropoulou, G. Ioannou, and G. P. Prastacos, "Enterprise Resource Planning implementation at Small and Medium Sized Enterprises: an initial study of the Greek market," International Journal of Integrated Supply Management, vol. 3, 2007, pp. 406.

[38] M. Argyropoulou, G. Ioannou, K. E. Soderquist, and J. Motwani, "Managing ERP system evaluation and selection in SMEs using the six-imperatives methodology," International Journal of Procurement Management, vol. 1, 2008, pp. 430-452.

[39] A. Deep, P. Guttridge, S. Dani, and N. Burns, "Investigating factors affecting ERP selection in made-to-order SME sector," Journal of Manufacturing Technology Management, vol. 19, 2008, pp. 430.

[40] A. Marsh, "The implementation of enterprise resource planning systems in small-medium manufacturing enterprises in South-East Queensland: a case study approach," in International Conference on Management of Innovation and Technology (ICMIT), vol.2, 2000, pp. 592-597.

[41] D. Reuther and G. Chattopadhyay, "Critical factors for enterprise resources planning system selection and implementation projects within small to medium enterprises," in International Engineering Management Conference, Vol.2, 2004, pp. 851-855.

[42] E. Bernroider and S. Koch, "ERP selection process in midsize and large organizations," Business Process Management Journal, vol. 7, 2001, p. 251.

[43] P. Hallikainen, H. Kivijaervi, M. Rossi, S. Sarpola, and J. Talvinen, "Selection of ERP Software in Finnish SME's," in Australasian Conference on Information Systems (ACIS), 2002.

[44] Y. van Everdingen, J. Hillegersberg, and E. Waarts, "ERP adoption by European midsize companies," Communication of the Association for Computing Machinery (CACM), vol. 43, 2000, pp. 27-31.

[45] K. A. Olsen and P. Sætre, "IT for niche companies: is an ERP system the solution?," Information Systems Journal, vol. 17, 2007, pp. 37-58.

[46] K. A. Olsen and P. Sætre, "ERP for SMEs - is proprietary software an alternative?," Business Process Management Journal, vol. 13, 2007, pp. 379-389.

[47] D. Sledgianowski, M. H. A. Tafti, and J. Kierstead, "SME ERP system sourcing strategies: a case study," Industrial Management and Data Systems, vol. 108, 2008, pp. 421.

[48] P. Iskanius, "Risk Management in ERP Project in the Context of SMEs," Engineering Letters, vol. 17, 2009.

[49] A. Winkelmann and K. Klose, "Experiences While Selecting, Adapting and Implementing ERP Systems in SMEs: A Case Study," in Americas Conference on Information Systems (AMCIS), 2008.

[50] J.-H. Wu and Y.-M. Wang, "Enterprise resource planning experience in Taiwan: an empirical study comparative analysis," in Hawaii International Conference on System Sciences (HICSS), 2003, pp. 10.

[51] S.-Y. Hung, S.-I. Chang, and P.-J. Lee, "Critical Factors of ERP Adoption for Small- and Medium-Sized Enterprises: An Empirical Study," in Pacific Asia Conference on Information Systems (PACIS), 2004.

[52] E. Bernroider and S. Koch, "Differences in Characteristics of the ERP System Selection Process Between Small or Medium and Large Organizatons," in Americas Conference on Information Systems (AMCIS), 2000.

[53] C. Doom, K. Milis, S. Poelmans, and E. Bloemen, "Critical success factors for ERP implementations in Belgian SMEs," Journal of Enterprise Information Management, vol. 23, 2009, pp. $378-406$.

[54] A. Nattawee and R. Siriluck, "Developing ERP implementation success factors of Thai SMEs," in GMSARN International Conference on Sustainable Development: Issues and Prospects for the GMS 2008.

[55] B. Snider, G. J. C. d. Silveira, and J. Balakrishnan, "ERP implementation at SMEs : analysis of five Canadian cases," International Journal of Operations and Production Management, vol. 29, 2009, pp. 4-29.

[56] A. Y. T. Sun, A. Yazdani, and J. D. Overend, "Achievement assessment for enterprise resource planning (ERP) system implementations based on critical success factors (CSFs)," International Journal of Production Economics, vol. 98, 2005, pp. 189.

[57] Y. Xia, P. Lok, and S. Yang, "The ERP implementation of SME in China," in 6th International Conference on Service Systems and Service Management, 2009, pp. 135-140.

[58] F. Adam and P. O'Doherty, "Lessons from enterprise resource planning implementations in Ireland - towards smaller and shorter ERP projects," Journal of Information Technology, vol. 15,2000 , pp. 305-316.

[59] G. Gable and G. Stewart, "SAP R/3 Implementation Issues for Small to Medium Enterprises," in Americas Conference on Information Systems (AMCIS), 1999.

[60] H. Liang and Y. Xue, "Coping with ERP-related contextual issues in SMEs: a vendor's perspective," The Journal of Strategic Information Systems, vol. 13, 2004, pp. 399-415.

[61] R. S. Chen, C. M. Sun, M. M. Helms, and W. J. Jih, "Role negotiation and interaction: an exploratory case study of the impact of management consultants on ERP system implementation in SMEs in Taiwan," Information Systems Management, vol. 25, 2008, pp. 159-173.

[62] S. C. L. Koh, A. Gunasek aran, and J. R. Cooper, "The demand for training and consultancy investment in SME-specific ERP systems implementation and operation," International Journal of Production Economics, vol. 122, 2009, pp. 241-254. 
[63] M. Ojala, I. Vilpola, and I. Kouri, "Risks and risk management in ERP Project - cases in SME Context," Business Information Systems (BIS), 2006.

[64] S.-W. Chien, C. Hu, K. Reimers, and J.-S. Lin, "The influ ence of centrifu gal and centrip etal forces on ERP project success in small and medium - sized enterprises in China and Taiwan," International Journal of Production Economics, vol. 107, 2007, pp. 380.

[65] C. Equey, R. J. Kusters, S. Varone, and N. Montandon, "Empirical Study of ERP Systems Implementations Costs in Swiss SMEs," in International Conference on Enterprise Information Systems (ICEIS), 2008.

[66] M. Newman and Y. Zhao, "The process of enterprise resource planning implementation and business process re engineering: tales from two Chinese small and medium sized enterprises " Information Systems Journal vol. 18, 2008, pp. 405 .

[67] R. Chan, "Knowledge Management for Implementing ERP in SMEs," in 3rd Annual SAP Asia Pacific, Institute of Higher Learning Forum, Sin gap ore, 1999.

[68] M. Quiescenti, M. Bruccoleri, U. La Commare, S. N. La Diega, and G. Perrone, "Business process - oriented design of enterprise resource planning ( ERP ) systems for small and medium enterprises," International Journal of Production Research, vol. 44, 2006, pp. 3797-3811.

[69] M. Y. Zain, "Minimizing the Problems of Enterprise Resource Planning (ERP) Implementation for Small to Medium Cigarette Company Through Framework for Applications of Systems Thinking (FAST)," Media Informatika, vol. 6, 2008.

[70] J. Esteves, "Establishing the relationship between enterprise systems benefits, business complexity, and business alignment in SMEs," in European and Mediterranean Conference on Information Systems (EMCIS), Costa Blanca, Alicante, Spain, 2006.

[71] J. Esteves, "Towards a Benefits Realization Roadmap for ERP Usage in Small and Medium-Sized Enterprises," in Americas Conference on Information Systems (AMCIS), 2007.

[72] J. Esteves, "A benefits realisation road - map framework for ERP usage in small and medium - sized enterprises," Journal of Enterprise Information Management, vol. 22, 2009, pp. 25.

[73] T. Federici, "ERPs in SMEs: Ex-post Evaluation of Success Factors " in European Conference on Information Systems (ECIS), 2007.

[74] T. Federici, "Factors influencing ERP outcomes in SMEs : a post - introduction assessment," Journal of Enterprise Information Management vol. 22, 2009, pp. 81.

[75] O. Gupta, K. Priy iadarshini, S. Massoud, and S. K. A grawal, "Enterprise resource planning: a case of a blood bank," Industrial Management and Data Sy stems, vol. 104, 2004,pp. 589-603.

[76] C. Equey and E. Fragnière, "Elements of Perception regarding the Implementation of ERP Systems in Swiss SMEs," International Journal of Enterprise Information
Systems, vol. 4, 2008, pp. 1.

[77] D. Sedera, G. Gable, and T. Chan, "ERP success: Does organisation Size Matter?," in Pacific Asia Conference on Information Systems (PACIS), Adelaide, South Australia, 2003.

[78] S. C. L. Koh and M. Simpson, "Change and uncertainty in SME manufacturing environments using ERP," Journal of Manufacturing Technology Management, vol. 16, 2005, pp. 629.

[79] S. C. L. Koh and M. Simpson, "Could enterprise resource planning create a competitive advantage for small businesses?," Benchmarking: An International Journal, vol. 14, 2007, pp. 59-76

[80] S. C. L. Koh and S. M. Saad, "Managing uncertainty in ERP-controlled manufacturing environments in SMEs," International Journal of Production Economics, vol. 101, 2006, pp. 109-127.

[81] D. Nathanael, B. Papantouniou, and D. Papageorgiou, "ERP implementation and actual work practice in SMEs: a dialectic perspective," in Stimulating Manufacturing Excellence in Small and Medium Enterprises (SMESME) Conference, 2003.

[82] V. Bohórquez and J. Esteves, "Analyzing SMEs Size as a Moderator of ERP Impact in SMEs Productivity," Communications of the IIMA, vol. 8, 2008, pp. 67-80.

[83] F. Rowe, R. El Amrani, M. Bidan, R. Marciniak, and B. Geffroy-Maronnat, "Does ERP Provide a Cross-Functional View of the Firm? Challenging Conventional Wisdom for SMEs and Large French Firms," in International Conference on Information Systems (ICIS), 2005.

[84] R. Seethamraju, "Enterprise System's Characteristics in Small and Medium-Sized Enterprises Context - A Case Study," in European and Mediterranean Conference on Information Systems (EMCIS), Al Bustan Rotana Hotel, Dubai Ravi, 2008.

[85] S. F. Huin, "Managing deployment of ERP systems in SMEs using multi-agents," International Journal of Project Management, vol. 22, 2004, pp. 511-517.

[86] S. de Burca, B. Fynes, and D. Marshall, "Strategic technology adoption: extending ERP across the supply chain," Journal of Enterprise Information Management, vol. 18, 2005, pp. 427-440.

[87] K. Metaxiotis, "Exploring the rationales for ERP and knowledge management integration in SMEs," Journal of Enterprise Information Management, vol. 22, 2009, pp. 51.

[88] H. Nach and A. Lejeune, "Implementing ERP in SMEs: Towards an Ontology Supporting Managerial Decisions," in International MCETECH Conference on eTechnologies 2008 , pp. 223-226.

[89] K. M. Eisenhardt, "Building Theories from Case Study Research", The Academy of Management Review, Vol. 14, No. 4, 1989, pp. 532-550. 